\title{
Consolidación y restauración de la fachada norte del Senado de España mediante reanclados, armados, sellados y coberturas
}

\section{Consolidation and restoration of the northern façade of the old Senate building using anchorages, reinforcements, renders, sealings and covers}

J. Monjo $^{(*)}, \underline{\text { R. Bustamante }}{ }^{(*)}$

\section{RESUMEN}

La consolidación y restauración de elementos existentes en la fachada norte del antiguo edificio del Senado de España se ha basado en el reanclado de las molduras macizas del recercado de huecos y de las molduras huecas de cornisas, ambas de piedra artificial, con varillas de poliéster reforzado con fibra de vidrio; en la eliminación del revoco existente y la realización de uno nuevo en dos capas, armando con malla de fibra de vidrio la capa base de cal hidráulica previamente a la aplicación de la capa de terminación de cal aérea; en la apertura de juntas de retracción selladas con silicona neutra, tanto de las molduras como del revoco, y en la cobertura de las superficies horizontales de los elementos salientes con chapa de zinc (molduras, guardapolvos y vierteaguas). Se exponen los estudios previos con los resultados de la documentación histórica, el análisis de los materiales y el diagnóstico de las lesiones que sustentan la intervención.

Palabras clave: Consolidación; restauración; reanclado; armado; junta; sellado; cobertura; Palacio del Senado.

\section{ABSTRACT}

The consolidation and restoration of existing elements in the northern facade of the old Senate building in Spain is based on the anchorage of the windows massive artificial stone frame and the crown hollow moulding with polyester rods reinforced with fiberglass; on the elimination of the existing plaster and making a new one in two layers, arming with fiberglass mesh the base hydraulic lime layer prior to application of the finish coat of air lime; on the opening of expansion joints sealed with neutral silicone, both the mouldings and the render, and on the cover of the horizontal surfaces of the projecting elements (mouldings, overalls and flashing) with zinc sheeting. Previous studies are discussed with the results of historical documentation, with the materials analysis and the diagnosis of damages that support the intervention.

Keywords: Consolidation; restoration; anchoring; mesh reinforcing; joint; sealant; cover; Senate Palace.

(*) Escuela Técnica Superior de Arquitectura - Universidad Politécnica de Madrid (España). Persona de contacto/Corresponding author: rosa.bustamante@upm.es (R. Bustamante).

Cómo citar este artículo/Citation: Monjo, J., Bustamante, R. (2015). Consolidación y restauración de la fachada norte del Senado de España mediante reanclados, armados, sellados y coberturas. Informes de la Construcción, 67(539): e100, doi: http://dx.doi.org/10.3989/ ic.14.078.

Licencia / License: Salvo indicación contraria, todos los contenidos de la edición electrónica de Informes de la Construcción se distribuyen bajo una licencia de uso y distribución Creative Commons Reconocimiento no Comercial 3.o. España (cc-by-nc). 


\section{INTRODUCCIÓN Y OBJETIVOS}

La consolidación es una intervención de reparación y de restauración destinada a la adición de un material para la mejora de la cohesión interna o de la estabilidad mecánica (1). En el caso que se expone se trataba de consolidar la fachada norte del edificio del Palacio del Senado de España, con todos los elementos que la constituyen. Para ello se identificaron las actuaciones necesarias, dirigidas fundamentalmente a recuperar ambas mejoras, tanto de las piezas semiempotradas de piedra artificial que constituían las molduras y embocaduras de ventanas, como de los morteros del revoco existente. Las piezas de piedra artificial presentaban roturas y peligro de desprendimiento, mientras que el revoco tenía numerosas fisuras y zonas también desprendidas.

La metodología empezó con la realización de los estudios previos: análisis de la documentación histórica, caracterización de materiales y sistemas constructivos, y diagnóstico de la causa de las lesiones, para finalizar con la intervención, que ha estado bajo la responsabilidad de los autores.

\section{ESTUDIOS PREVIOS}

\subsection{La memoria histórica}

Los principales cambios de configuración de la fachada se han registrado en el tramo central, en donde se encuentra la escalera, manteniendo con toda probabilidad los huecos que corresponderían a los del antiguo convento Agustino construido a fines del siglo XVI, antes de convertirse en palacio del Senado en el siglo XIX, excepto el extremo oeste, que corresponde al testero de una crujía que se levantaba paralela a la calle Bailén y que aparece en el plano de Madrid de Alfonso XII.

La fachada después de la Guerra Civil fue modificada de acuerdo a un proyecto de restauración del palacio, sede del Consejo Nacional en esa época, redactado en 1951 por el ar- quitecto conservador Manuel Ambrós Escanellas (2). En el presupuesto se proponían molduras de piedra artificial para todos los huecos aunque la medición de metros lineales de faja y de cornisa de coronación da a entender que no se incluía el extremo oeste (separado actualmente por una junta constructiva). Sin embargo, y dado que se desconoce la fecha concreta de ejecución, lo más probable es que la intervención haya tenido lugar más adelante y abarcado toda la fachada, tal como se aprecia en la Figura 1.

La parte central correspondiente a la escalera, sería modificada posteriormente en la intervención realizada por el arquitecto conservador Salvador Gayarre para conectar el antiguo con el nuevo edificio que empezó a construirse en 1987. Para ello se eliminaron cinco ventanas del sótano y se adoptó una decoración más sencilla, que persiste actualmente, con un óculo en la parte superior (Figura 2). Asimismo, se modificó el zócalo o frente del segundo sótano. En 1996 siendo arquitecto conservador Carlos García Tolosana se rehabilitó el extremo oeste de la fachada, por lo que se modificaron parcialmente algunos forjados en la planta baja y se hizo un nuevo falso techo en esta planta que obligó a reducir la altura de los balcones, bajando los guardapolvos de los huecos a su cota actual.

\subsection{Caracterización de los materiales y elementos constructivos}

Se planificó la realización de catas cilíndricas de $70 \mathrm{~mm}$ de diámetro (dimensiones usuales en la extracción de testigos), principalmente en los lugares que presentaban alteraciones, para determinar los materiales y características de los elementos constructivos. Dada la imposibilidad para introducir una plataforma para la toma de muestras, se realizó en las verticales de descenso de un escalador con las limitaciones que ello implica (Figura 3). La fachada tiene 25,50 m de altura por 91,50 m de longitud desde la calle del Reloj hasta la de Bailén, más $5 \mathrm{~m}$ orientados al Oeste.

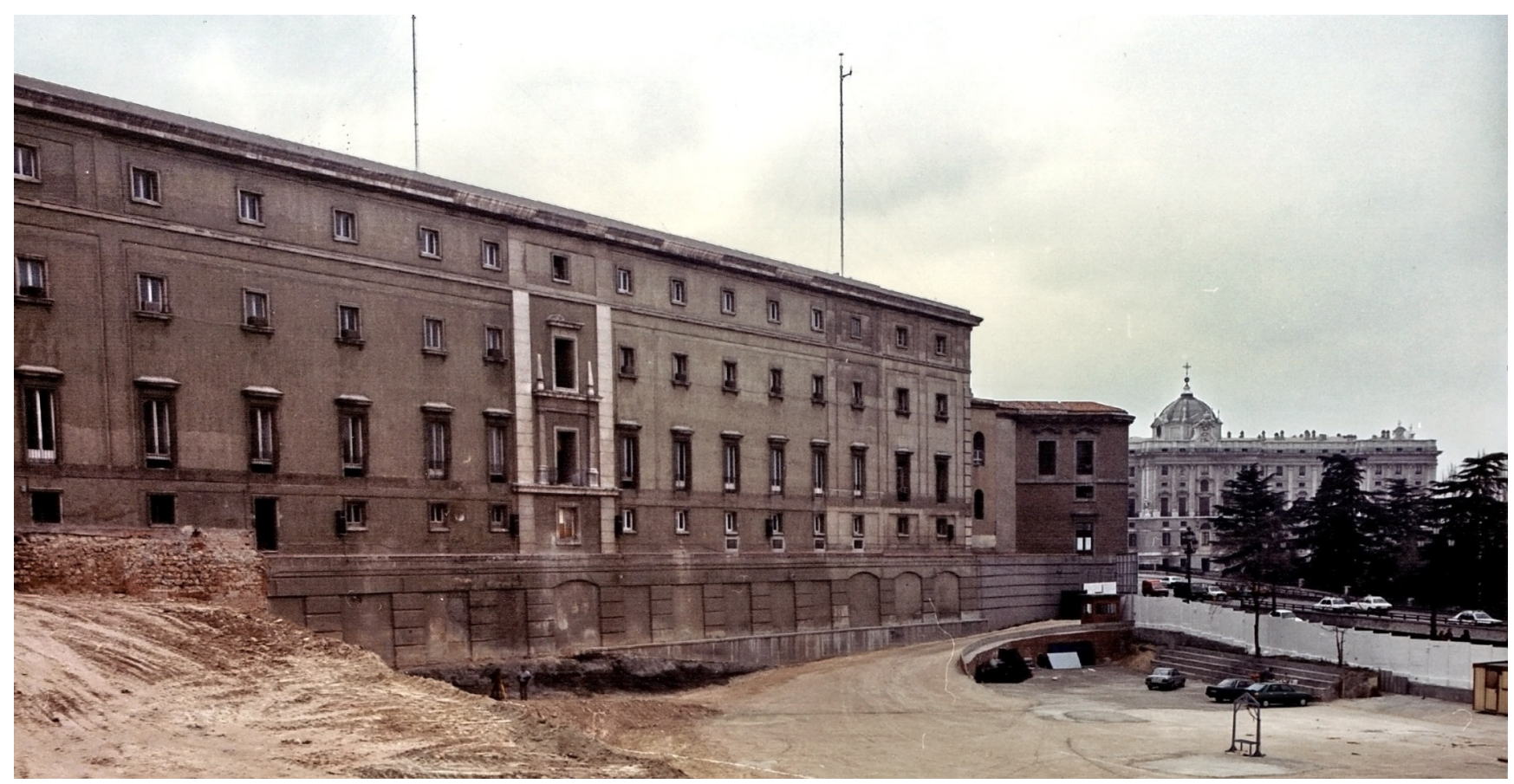

Figura 1. Fachada Norte del Senado de España, 1987 (fuente: Senado). 


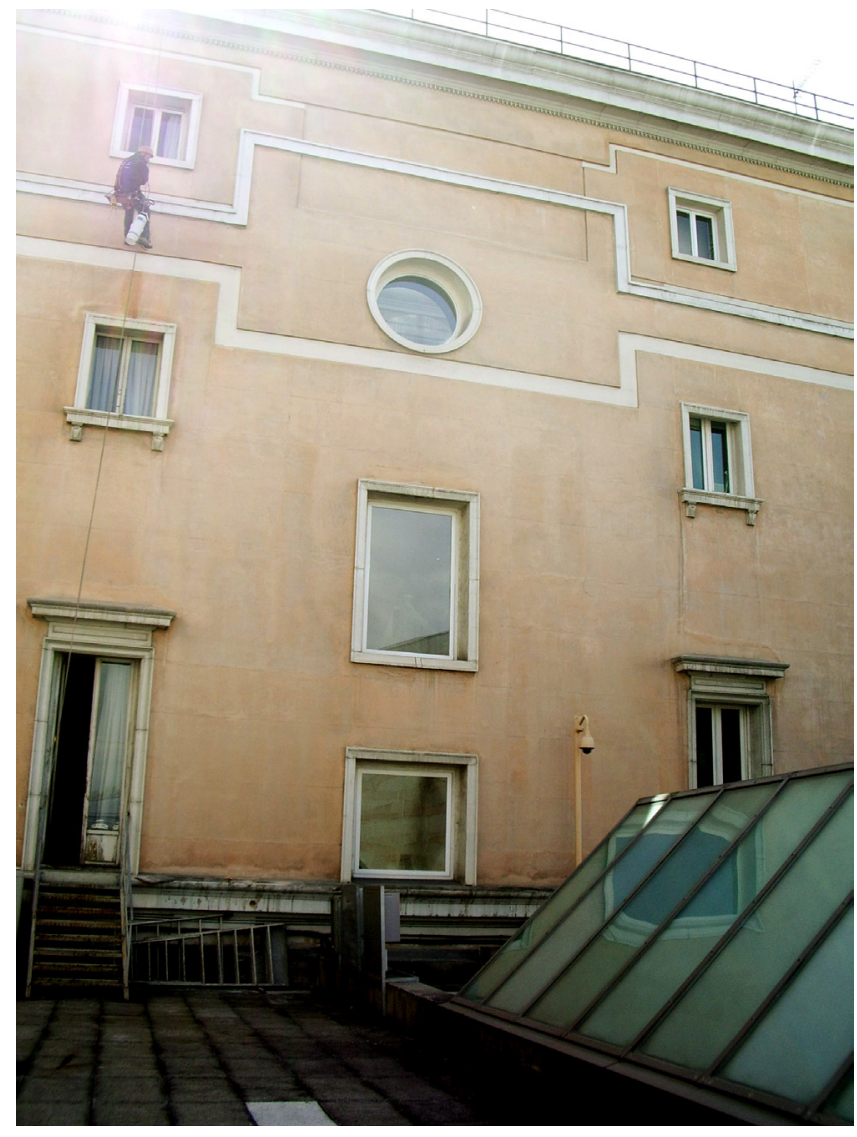

Figura 2. Situación de las muestras obtenidas en la fachada norte.

Las muestras se sometieron a ensayos de caracterización física, hídrica, mecánica y de ultrasonidos que se presentan en la Tabla 1, ordenadas por identificación y emplazamiento en fachada. Ensayos para la determinación de la densidad aparente de acuerdo a la norma UNE EN 1015-10, del coeficiente de absorción de agua por inmersión ( $\mathrm{C}_{\mathrm{a}}$ ), UNE-EN 14617-1, del coeficiente de absorción de agua por capilaridad $\left(\mathrm{C}_{\mathrm{c}}\right)$, UNEEN 1015-18, de la resistencia a compresión, UNE-EN 1015-11, y UNE EN 12504-4 para la medición ultrasónica. Esta última se llevó a cabo con un equipo calibrado Tico, operando a $0,5 \mathrm{kV}$ para la obtención del módulo de elasticidad dinámico $\left(\mathrm{E}_{\text {din }}=\rho \cdot \mathrm{v}^{2}\right)$.
Con los análisis de difracción de rayos X (DRX) se determinaron los componentes mayoritarios y con el de granulometría, la composición en peso del mortero a partir de la relación entre la fracción fina (conglomerante) y la fracción gruesa (arena) que se realiza en base al método tradicional por machaqueo de la muestra (3). Los resultados aportan la dosificación aproximada en volumen que manifiesta un bajo contenido del material cementante (pasta hidratada), por ejemplo para la muestra 16.

Estos ensayos, análisis e información previa eran necesarios, primero para definir los materiales conformados en taller y en obra, y luego para determinar el estado de conservación, que se describen a continuación:

a) Las molduras macizas, de piedra artificial o aglomerada, presentan resultados altos en la velocidad ultrasónica que demuestran su compacidad, $2.796 \mathrm{~m} / \mathrm{s}$ (muestra 16) y $2.143 \mathrm{~m} / \mathrm{s}$ (muestra 27). Asimismo, según el DRX realizado, se confirma que las de piedra artificial con calcita como cementante y cuarzo como árido, tienen un $\mathrm{E}_{\text {din }}$ de 15,24 GPa (muestra 16) mayor al de los fabricados con árido de mármol, 10,14 GPa y 6,76 GPa (muestras 27 y 29 respectivamente), materiales estos últimos similares a los de las molduras de los recercados de las ventanas a consolidar. El DRX de la cenefa decorativa se aprecia en la Figura 4, correspondiente a la parte cementante.

b) Las molduras huecas de cornisas, con espesores de paredes variables, corresponden a diferentes tipos: unas de una sola pieza (muestra 29), otras de dos piezas (frente y tapa) con horquillas embutidas en el interior del frente para su sujeción al muro soporte, y la tapa hecha generalmente con una rasilla amorterada, y otras de tres piezas, como la cornisa superior, con base semiempotrada, frontal y tapa. El DRX de la tapa de la pieza de la cornisa inferior, que carecía de protección impermeabilizante (muestra 20), determinaba calcita y yeso como cementantes, con presencia de ettringita, que procedería del cemento utilizado. La mayoría de estas piezas son de piedra artificial, pero existen algunas partes de cornisa hechas con mortero sobre rasilla como la muestra 15 que presentaba un alto módulo de elasticidad dinámico, $11,13 \mathrm{GPa}$.

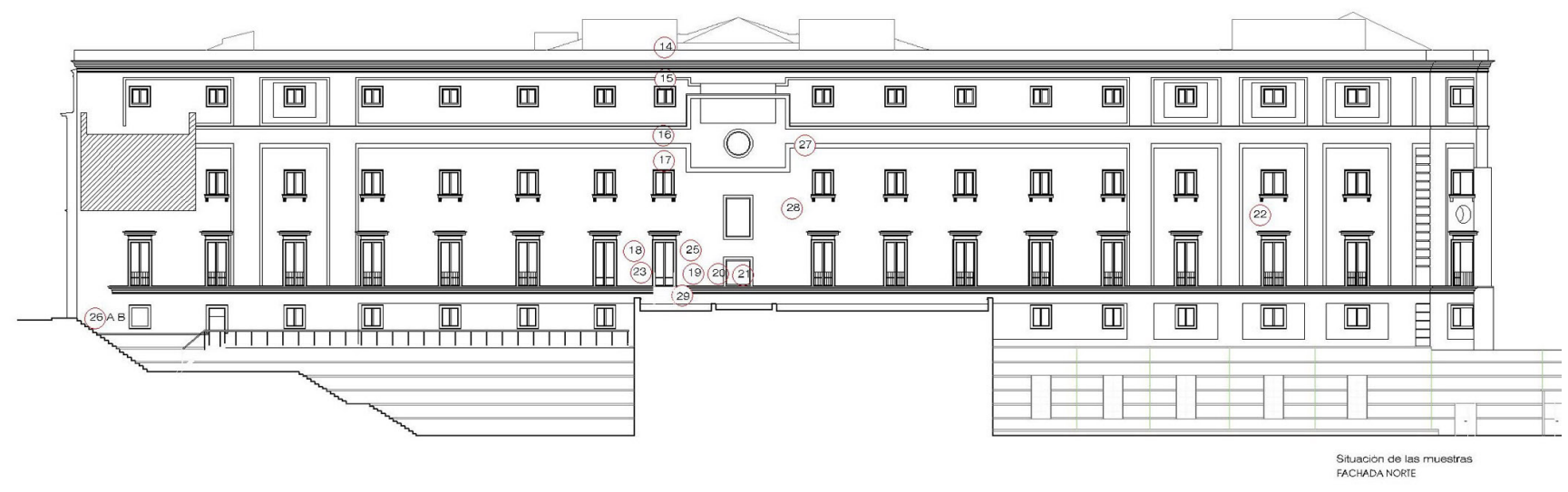

Figura 3. Centro de la fachada Norte (toma de muestras, abril 2009). 
Tabla 1. Resultados de los ensayos físicos, hídricos y mecánicos de la fachada Norte (laboratorio de Materiales de la ETSAM).

\begin{tabular}{|c|c|c|c|c|c|c|c|c|c|}
\hline 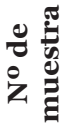 & 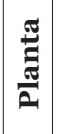 & Elemento constructivo & $\underset{\mathrm{g} / \mathbf{c m}^{3}}{\rho}$ & $\begin{array}{c}\mathrm{Ca} \\
\%\end{array}$ & $\begin{array}{c}\mathrm{Cc} \\
\mathrm{g} / \mathrm{cm}^{2} \cdot \mathbf{m i n}^{-0,5}\end{array}$ & $\begin{array}{l}\sigma_{\text {com }} \\
\text { MPa }\end{array}$ & $\begin{array}{l}\text { Ultra- } \\
\text { sonidos } \\
\text { m/s }\end{array}$ & $\underset{\text { GPa }}{\text { Edin }}$ & $\begin{array}{l}\text { Dosificación } \\
\text { en volumen }\end{array}$ \\
\hline 14 & 2 & $\begin{array}{l}\text { Mortero bajo lámina de aluminio, s/rasillón } \\
\text { de tapa de cornisa }\end{array}$ & 1,83 & 3,68 & 0,020 & 14,20 & 1.607 & 4,73 & \\
\hline 15 & 2 & $\begin{array}{l}\text { Amorterado (1) de friso } \mathrm{s} / \text { rasilla de cornisa } \\
\text { superior } \mathrm{e}=20 \mathrm{~mm}\end{array}$ & 2,10 & 5,97 & 0,030 & 25,10 & 2.303 & 11,13 & \\
\hline 16 & 2 & $\begin{array}{l}\text { Franja decorativa saliente de piedra artificial } \\
\mathrm{e}=40 \mathrm{~mm} \text { más } 8 \mathrm{~mm} \text { de capa de acabado }\end{array}$ & 1,95 & 7,45 & 0,083 & 1,42 & 2796 & 15,24 & $1: 6$ \\
\hline 27 & 1 & $\begin{array}{l}\text { Prefabricado de mármol artificial de cenefa } \\
\text { rehundida bajo óculo }\end{array}$ & 2,21 & 6,31 & 0,021 & - & 2143 & 10,14 & $1: 2^{1 / 2}$ \\
\hline 22 & 1 & $\begin{array}{l}\text { Enfoscado lado oeste (menor antigüedad) } \\
\mathrm{e}=20,65 \mathrm{~mm} \text {; revoco conformado por } 1 \text { capa } \\
\text { fina blanca } \mathrm{e}=3,50 \mathrm{~mm} \text { y capa final rosa } \\
\mathrm{e}=1,62 \mathrm{~mm} \text {. }\end{array}$ & 2,02 & 6,09 & 0,033 & - & 1715 & 5,94 & $1: 4^{1 / 2}$ \\
\hline $17 \mathrm{~A}$ & 1 & Enfoscado tramo central sobre cenefa & 2,02 & 3,83 & - & - & - & - & \\
\hline 18 & B & $\begin{array}{l}\text { Enfoscado tramo central e }=57 \mathrm{~mm} \text { y revoco } \\
4 \mathrm{~mm} \text { sobre cornisa inferior }\end{array}$ & 1,96 & 5,18 & 0,052 & - & 2060 & 8,30 & $1: 3$ \\
\hline 19 & B & Mortero tapa cornisas s/rasillón & 2,02 & 6,82 & 0,036 & 8,60 & 2243 & 10,15 & \\
\hline 20 & B & Mortero platabanda cornisas s/rasillón & 2,01 & 6,67 & 0,034 & - & 2357 & 11,17 & 1:5 \\
\hline 29 & B & $\begin{array}{l}\text { Prefabricado de mármol artificial, platabanda } \\
\text { cornisa inferior }\end{array}$ & 2,20 & 3,98 & - & - & 1753 & 6,76 & \\
\hline
\end{tabular}

e = espesor; B: planta baja. (1) uso de encofrado.

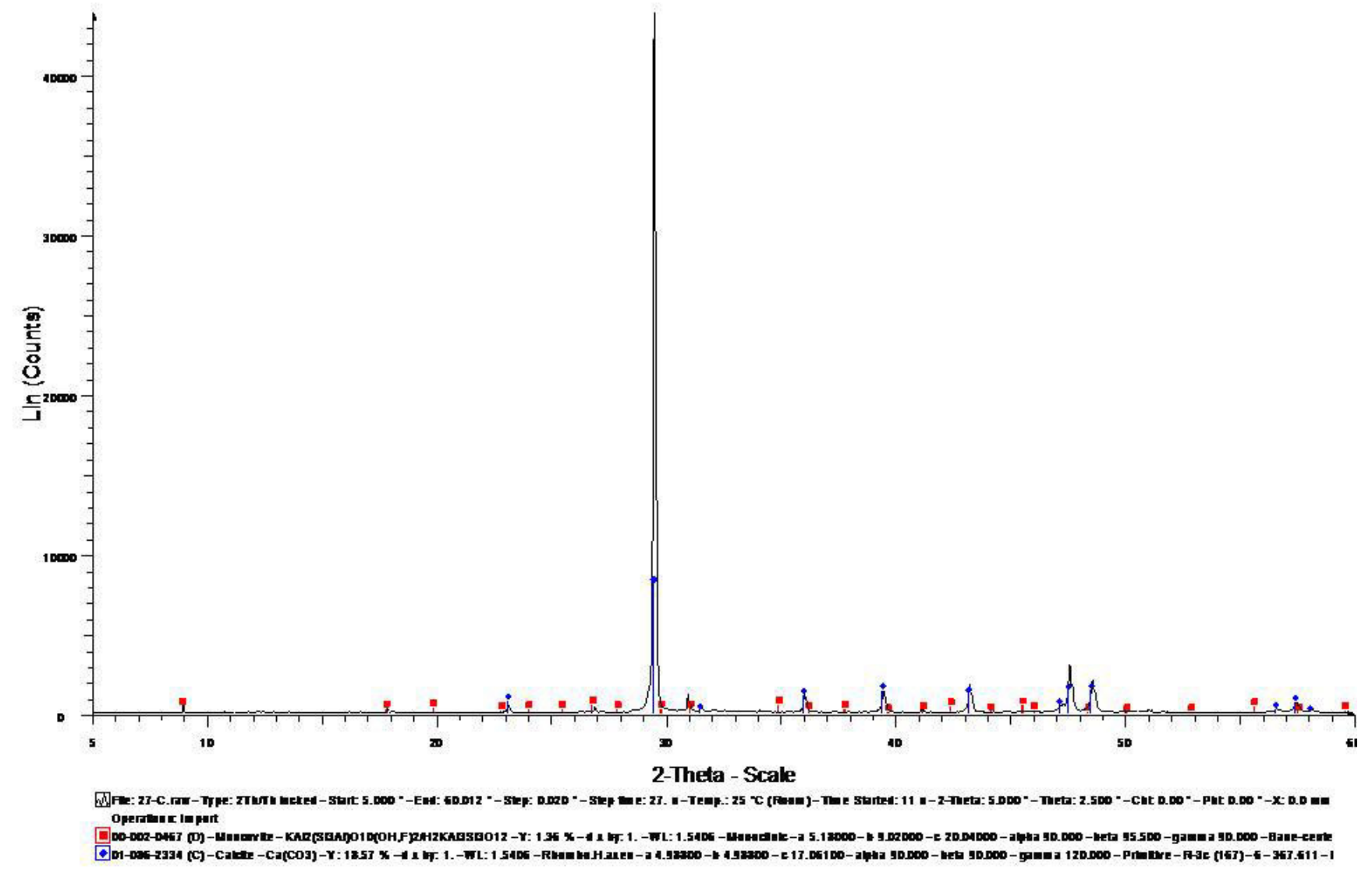

Figura 4. DRX de la muestra 27: calcita como cementante

c) Los morteros de enfoscados, de cemento y bastardos, aplicados sobre la fábrica de ladrillo, presentan módulos de elasticidad dinámico variables, entre 5,94 GPa y 8,30 GPa. El DRX de la muestra 18 confirmaba la presencia de calcita y yeso en la parte cementante y cuarzo y moscovita en el árido. d) El mortero del revoco de color rosa, de cal según el DRX efectuado, estaba compuesto por carbonato cálcico (calcita) con presencia significativa de cuarzo para la parte este (muestra 22) y mayoritariamente de calcita para la parte oeste (muestra 23). 


\subsection{Diagnóstico y propuesta de intervención}

Nos encontramos ante una solución constructiva que se corresponde con las vicisitudes y los cambios que ha sufrido. Se trata de una fachada portante de fábrica de ladrillo, que dispone de un enfoscado de regularización a base de mortero de cemento con muchas variaciones, aplicado en distintas oportunidades en la segunda mitad del siglo XX, a partir de las reformas iniciadas en 1951 (4), hasta la última de 1996, y de un revoco de mortero de cal, también con algunas variaciones. Por otra parte, la decoración resuelta con elementos prefabricados de piedra artificial conforma distintos elementos agrupados en tres tipos: dos molduras huecas corridas, una superior y otra inferior; una serie de franjas decorativas intermedias, unas en relieve y otras rehundidas formando entrecalles; finalmente embocaduras en todos los huecos de ventana, también con piedra artificial, para constituir jambas, dinteles y vierteaguas, incluso guardapolvos en los balcones de planta baja.

El estado constructivo presentaba algunas deficiencias, de las que cabe destacar las siguientes:

- Fisuras en mapa generalizadas en el revoco, debidas a las retracciones por cambios de humedad y temperatura.

- Fisuras locales más o menos lineales, donde se ha realizado algún añadido o variación del muro.

- Desprendimientos puntuales de dicho revoco, normalmente a partir de las fisuras.

- Fisuras en las piezas de embocaduras de los huecos de ventana, y en las molduras corridas superior e inferior, con desprendimientos parciales en la superior.

- Erosión en la moldura corrida inferior y en las franjas decorativas intermedias en relieve.

En conjunto podemos realizar el siguiente diagnóstico:

- El soporte original es firme aunque presenta añadidos y arreglos diversos que propician la aparición de fisuras por discontinuidad del soporte.

- El mortero de cemento que regulariza la base de ladrillo es demasiado rico, con un módulo de elasticidad alto que provoca fisuras de retracción higrotérmica en mapa.

- Las molduras corridas no disponen de juntas de retracción que reduzcan la variación dimensional, lo que provoca apertura de juntas entre piezas y fisuras perpendiculares a la dirección principal.

- Las embocaduras de los huecos de ventana no marcan las juntas constructivas, lo que provoca la aparición de fisuras, así como la apertura de las juntas constructivas entre piezas en los huecos más grandes.

- La falta de protección impermeable de las molduras corridas, inferior e intermedias, propicia la filtración de agua y su consiguiente erosión.

Por todo ello, la consolidación propuesta comprendía:

Reanclado de elementos prefabricados de cornisas para reducir el riesgo de desprendimientos (5), así como en molduras decorativas, y embocaduras y guardapolvos de ventanas.

Reparación de fisuras existentes en las piezas, mediante el sellado de las mismas con micromortero y patinado general protector.
Apertura y sellado de juntas de retracción en molduras, con el objeto de reducir las variaciones dimensionales por cambios higrotérmicos, sobre todo en los elementos de gran longitud, y evitar su fisuración y apertura de juntas constructivas, impidiendo la filtración de agua de lluvia.

Aplicación de nuevo revoco general, picando el actual, siempre que su eliminación no deteriore la fábrica de ladrillo, asegurando la correcta composición del soporte, con renovación, si cabe, del enfoscado base y aplicación del nuevo revoco liso lavado de cal, como el que presentaba antes de la restauración.

Establecimiento de una modulación del nuevo revoco y de su enfoscado base, que incorpore juntas de retracción profundas, para evitar la fisuración de paños continuos.

Cobertura de cornisas, guardapolvos de ventanas y alféizares con chapa de zinc, para evitar la filtración de agua de lluvia en esos planos salientes, cumpliendo las siguientes condiciones: engatillada en todas las uniones entre chapas, faldón plegado hacia arriba en su encuentro con el plano vertical de la fachada, de una altura mínima de $5 \mathrm{~cm}$, y anclado al mismo, sellando su unión, para proteger la junta constructiva del elemento saliente con el revoco, y goterón en su parte frontal, con un vuelo no inferior a $2 \mathrm{~cm}$.

\section{INTERVENCIÓN}

\subsection{Reanclado de molduras huecas}

En la realización de la obra se verificó que existían hasta cinco tramos de ejecución diferentes en la cornisa superior, el de piedra artificial se presenta en la Figura 5, y otros tramos más cortos de mortero sobre rasilla con pescantes interiores de sujeción. Este aspecto no hubiera sido posible de verificar en los estudios previos al desconocer los cambios registrados en toda su longitud. Sin embargo, la propuesta inicial de intervención fue igualmente válida, modificando la situación de las varillas de reanclado según el tipo de solución constructiva.

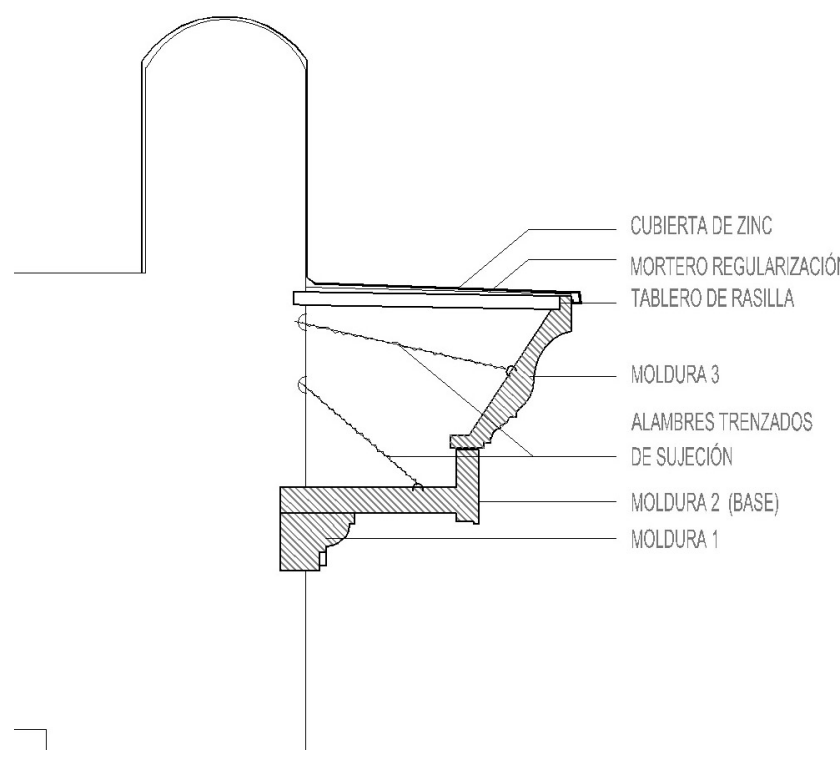

Figura 5. Estado anterior de un tipo de moldura sin pescantes de sujeción. 
La consolidación de la estabilidad de las piezas para asegurar su unión con la fábrica de ladrillo, se realizó mediante varillas corrugadas pultruídas de poliéster reforzado con fibra de vidrio (Figura 6), de 8 y $12 \mathrm{~mm}$ de diámetro, con 80 \% fibra y $20 \%$ de resina, siendo su resistencia a tracción de 760 Mpa y 690 Mpa respectivamente, carga máxima de 46 kN y $100 \mathrm{kN}$ respectivamente y módulo de elasticidad entre $35 \mathrm{GPa}$ y $41 \mathrm{GPa}(6)$.

Para ello se realizó una perforación en sentido ascendente, calando el grueso de la pieza frontal de la cornisa para introducir la varilla hasta un mínimo de $10 \mathrm{~cm}$ en la pared asegurando el empotramiento con resina epoxídica bicomponente sin estireno. El taladro en la pieza se abocardó para que la resina hiciera de tope y se colocó un encamisado de $15 \mathrm{~cm}$ en el extremo interior de la varilla para evitar el desprendimiento de la resina. En el abocardado exterior se aplicó finalmente un mortero de restauración que sellaba la perforación una vez finalizada la inserción, dejando la textura existente similar a la del resto de la moldura.

En la cornisa superior de mayor vuelo, $90 \mathrm{~cm}$, con pieza base empotrada y pieza frontal sujeta con alambre trenzado, en

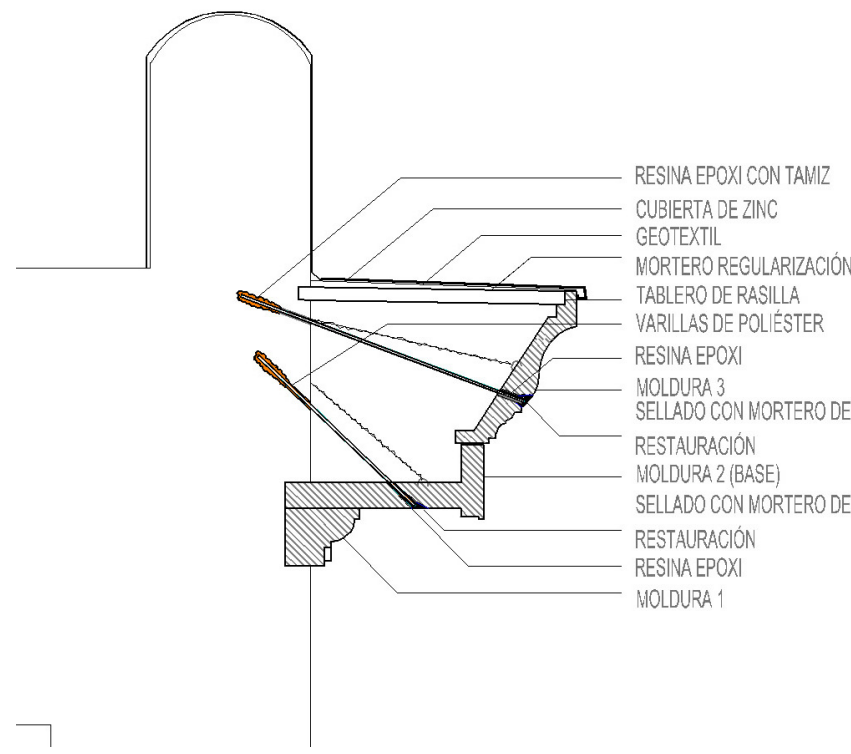

Figura 6. Consolidación de reanclado con varillas.

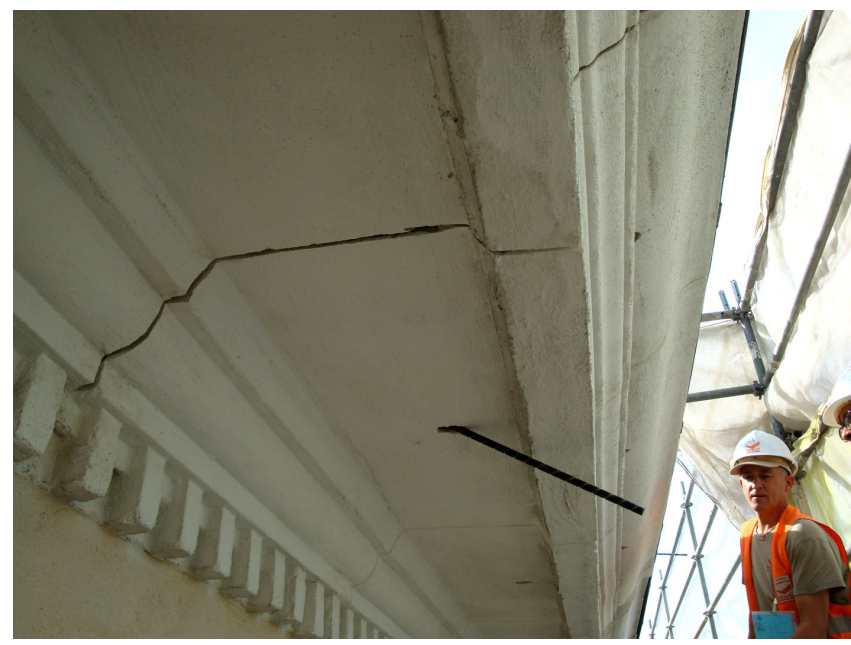

Figura 7. Anclaje que atraviesa la moldura base. avanzado estado de corrosión, se realizó un doble cosido: dos varillas en la base y otras dos en la pieza frontal (Figuras $7 \mathrm{y}$ 8). En cuanto a la moldura corrida inferior, al ser las piezas de menor dimensión, se realizó el anclado con una sola varilla por pieza.

\subsection{Reanclado de molduras macizas}

El mismo sistema de reanclado fue aplicado para las molduras macizas (Figuras 9 y 10); dos anclajes por pieza, tanto horizontal como vertical, usando similar resina y rehundiendo el cierre de la varilla para aplicar mortero de restauración y sellar, imitando la textura del resto de la moldura.

Sin embargo, los guardapolvos de los balcones no se reanclaron según lo previsto, pues las piezas carecían de entrega y estaban colgadas con esparto y escayola de un cargadero metálico, por lo que se procedió a retirar los anclajes de escayola y sustituirlos por pletinas de acero inoxidable soldadas al mismo cargadero, ahora protegido contra la oxidación (Figura 11).

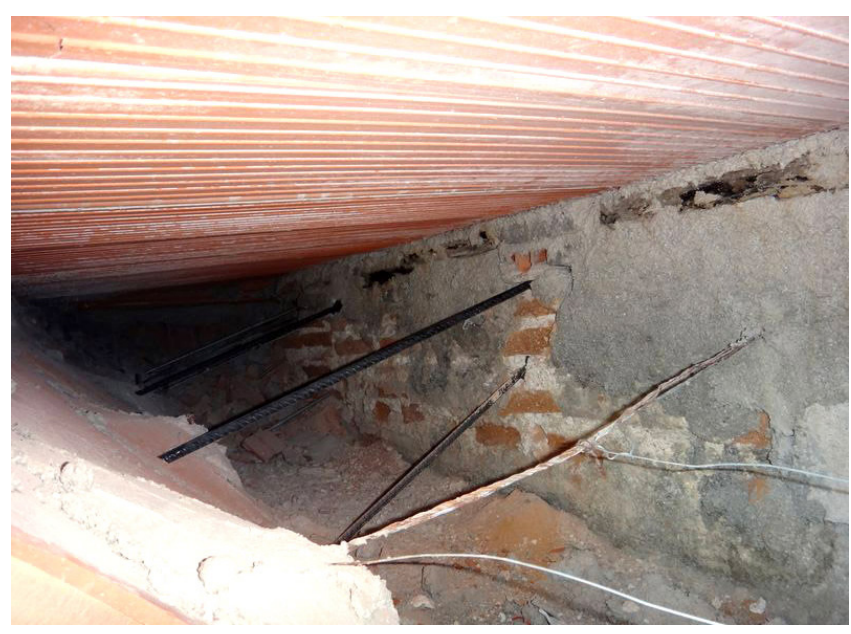

Figura 8. Varillas de reanclado atravesando la pieza hasta alcanzar el muro soporte.

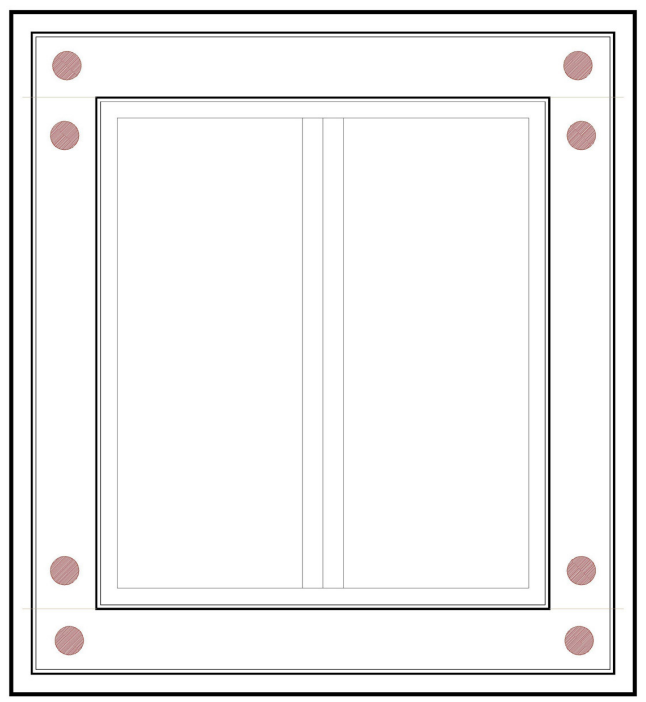

Figura 9. Propuesta de reanclado. 


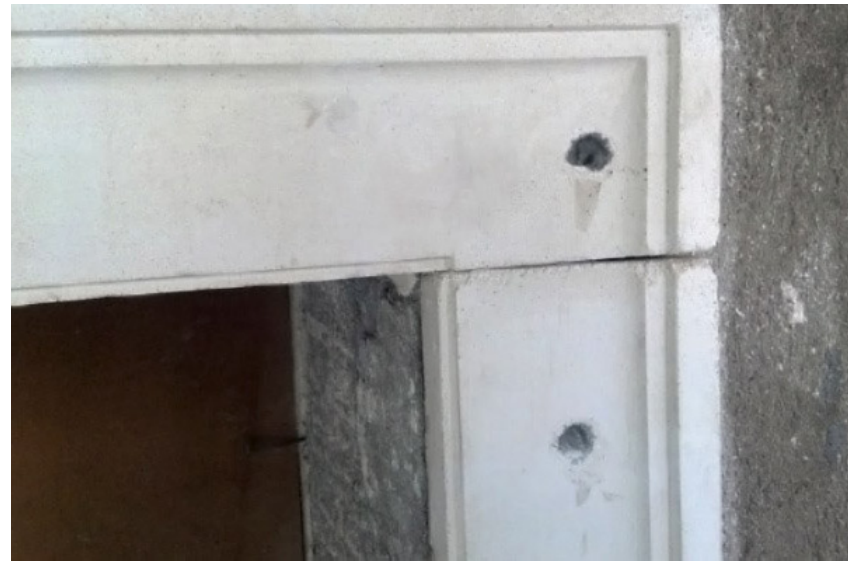

Figura 10. Ejecución de reanclado de embocadura de ventana.

\subsection{Apertura de juntas, rejuntado de uniones y sellado de molduras}

Tanto en las cornisas huecas como en las molduras macizas se eliminó el mortero de juntas entre piezas y se procedió a rejuntar nuevamente con mortero de restauración a base de cal, dejándolas marcadas con un ligero rehundido. Por otra parte, se fijaron juntas elásticas de retracción cada cuatro piezas o $4 \mathrm{~m}$ de distancia aproximadamente, siempre coincidiendo con las juntas entre piezas, utilizando para el sellado una silicona de reticulación neutra, por su elongación a rotura de $600 \%$ (DIN 53504) (Figura 12).

\subsection{Reproducción y reposición de piezas dañadas}

La reintegración de las partes más dañadas de las molduras (Figura 13), se realizó con mortero de restauración compuesto por conglomerantes hidráulicos, arena y aditivos seleccionados, cuyas características son las siguientes:

- Granulometría 0,080 mm: 60 a $70 \%$, 0,5 mm < $10 \%$ y $1,25 \mathrm{~mm}<1 \%$

- Resistencia a compresión: 5 a 7 Mpa

- Resistencia a tracción: 1,5 a 3,7 Mpa

- Densidad aparente: 1,5 a $1,7 \mathrm{~g} / \mathrm{cm}^{3}$

- Módulo de elasticidad: 3,5 a 5,5 GPa.

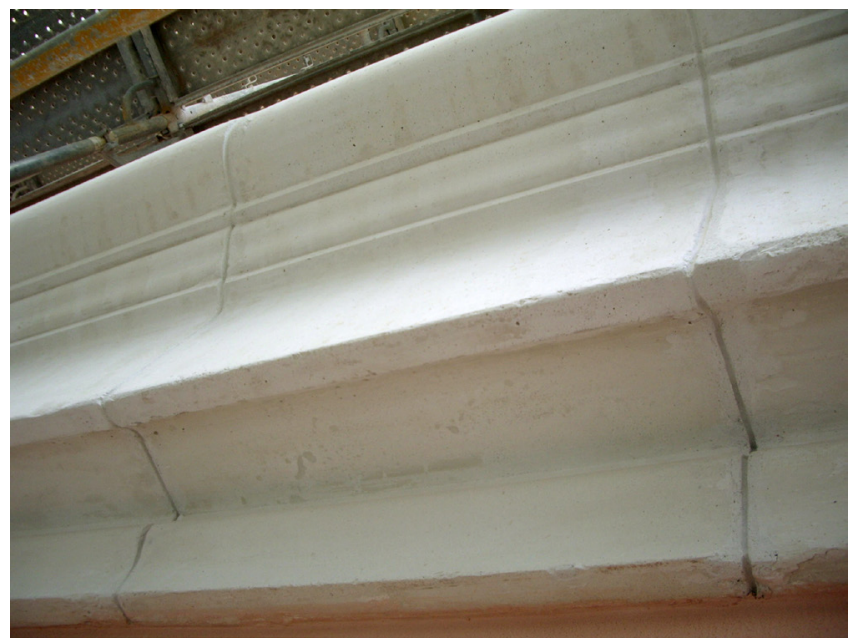

Figura 12. Juntas de cornisa superior.

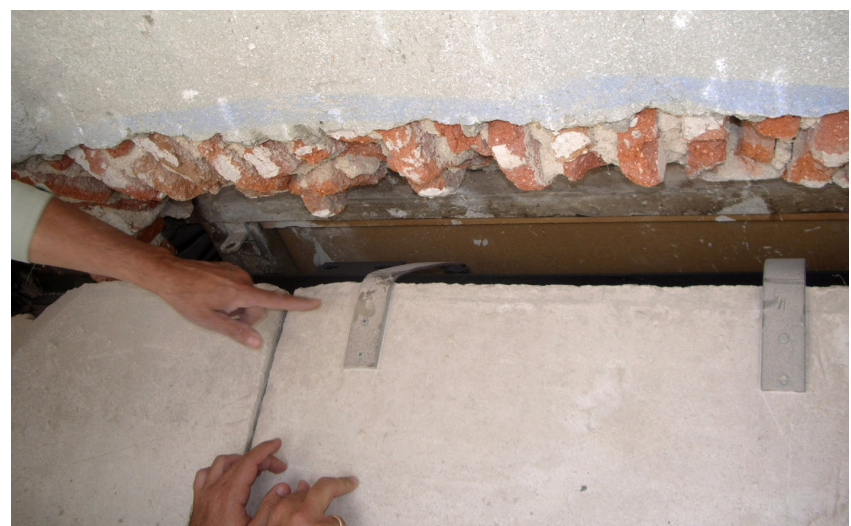

Figura 11. Piezas del guardapolvo reancladas con pletinas de acero inoxidable.

Por su parte, la reproducción de las réplicas para sustituir las piezas rotas se realizó con elementos prefabricados de material similar al de la piedra artificial original, con mortero bastardo de cemento blanco y árido de mármol, con la ayuda de un molde de poliéster.

\subsection{Preparación de la base del nuevo revoco, armado de la primera capa y apertura de juntas de retracción}

El repicado total del revoco comprendía la eliminación del enfoscado existente que cubría gran parte de la fachada, pero dada la dureza y espesor del mismo, con el excesivo coste de su eliminación, se optó por mantenerlo y proceder a un tratamiento especial para evitar la aparición de fisuras. Para ello, en primer lugar, se procedió a abrir y rellenar las fisuras existentes, utilizando un mortero bastardo 1:3 elaborado en el sitio, siendo la composición del conglomerante de 0,5 de hidróxido de calcio y 0,5 de cemento Pórtland.

En segundo lugar, y dada la diferencia de retracción entre el mortero de cemento y el de la cal cálcica del revoco final, se aplicó una capa intermedia a base de cal hidráulica NHL 3,5 (módulo de elasticidad de 5 a $7 \mathrm{GPa}$, inferior al del mortero de cemento existente, según la muestra 18 de caracterización),

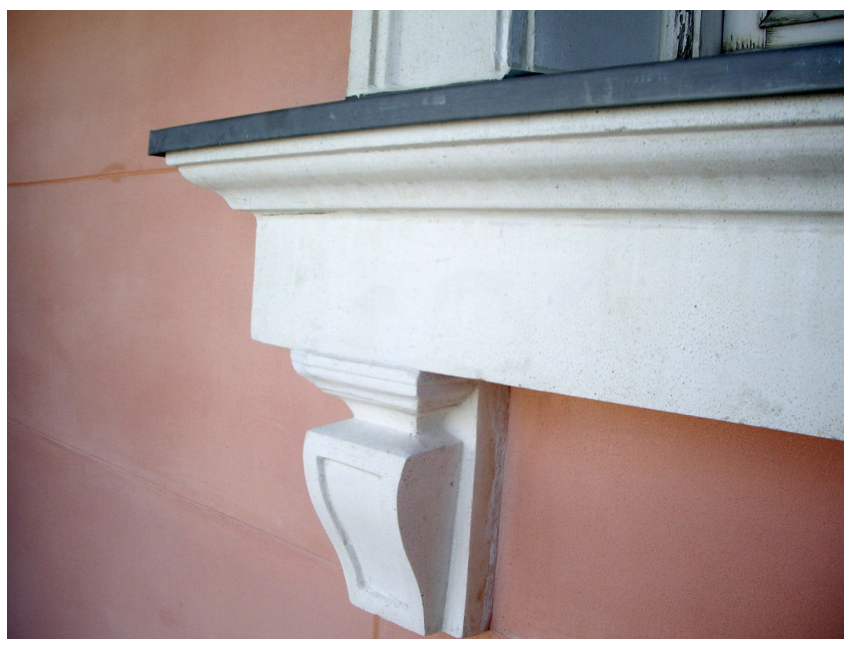

Figura 13. Alféizar y peana restaurados. 
que actuaría de base para recibir la capa final, cuyo módulo de elasticidad era inferior a $4 \mathrm{GPa}$. Aunque al inicio de la intervención no se decidió armar esta capa base en su totalidad, sin embargo, pronto se tomó la decisión de hacerlo con malla de fibra de vidrio (Figura 14) para evitar la aparición de microfisuras en el revoco de terminación, que reflejaban las que se producían en el mortero de cemento antes de abrir las juntas de retracción y que se transmitían a través de la capa base sin armar, acentuándose en el revoco final al absorber la humedad del ambiente.

El espesor del mortero de cemento existente es de $1 \mathrm{~cm}$ a $4 \mathrm{~cm}$, y el del conjunto de la capa base, con la malla insertada y capa de terminación, varía entre $5 \mathrm{~mm}$ y $10 \mathrm{~mm}$.

Finalmente, para evitar fisuras por retracción higrotérmica, se procedió a la apertura de juntas de retracción relativamente próximas. Para ello, una vez endurecida la capa base, se procedió al corte con radial de las juntas programadas, corte que se reproducía en la capa de terminación, abriendo juntas verticales y horizontales de $2,5 \mathrm{~cm}$ a $3 \mathrm{~cm}$ de profundidad, cortando totalmente la capa base con malla y un espesor suficiente de la capa del enfoscado, sin necesidad de utilizar junquillos (Figura 15). Las juntas verticales coincidían con el eje del paño entre ventanas y con las jambas de los huecos, y las horizontales con la modulación de la base y el dintel de los mismos. Estas juntas, que dejan paños de $1,30 \mathrm{~m}$ por $1,80 \mathrm{~m}$ y de $1,60 \mathrm{~m}$ por $1,80 \mathrm{~m}$, se sellaron con silicona neutra del mismo color que el del revoco.

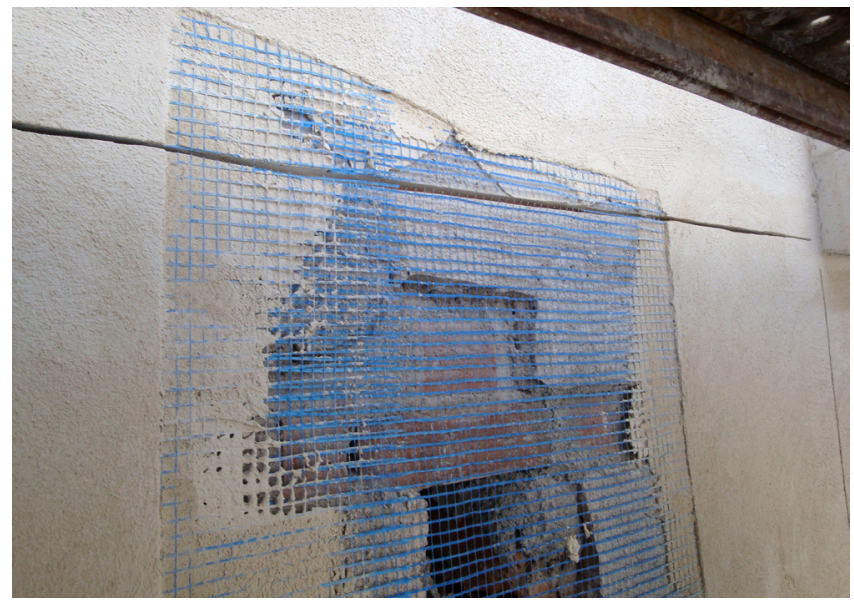

Figura 14. Malla de armado de la capa base.

\subsection{Composición de la capa de terminación del revoco}

Son $14 \mathrm{~kg}$ de cal (Calcinor) para $47 \mathrm{~kg}$ de marmolina Macael (El Molino), de tamaño máximo $1 \mathrm{~mm}$ según el análisis granulométrico de áridos (UNE-EN 933-1:2012). El apagado de la cal se realizó en taller pero se mejoró mediante el enfosado en bidones en obra, calculándose el volumen a utilizar para garantizar la uniformidad. Pigmentada en la proporción de $112 \mathrm{~g}$ de hierro óxido amarillo Bayferrox-920, $18 \mathrm{~g}$ de hierro óxido negro Bayferrox-318 y 56 g de hierro óxido rojo Bayferrox-130. La cal calcítica CL $70 \mathrm{~S}$ contiene $74,4 \%$ de óxido de calcio más óxido de magnesio, según el análisis químico realizado (UNE EN 459-1).

Los resultados de caracterización mecánica a los 30 días son menores a los del enfoscado analizado en los estudios previos, pero idóneos para un material de acabado que debe soportar las deformaciones a que está sometido y de lento endurecimiento. Igualmente son menores los de velocidad a ultrasonidos y el módulo de elasticidad dinámico, como se aprecia en la Tabla 2 (7).

La adhesión de los morteros rosa y blanco (este último aplicado en las embocaduras de ventanas y entrecalles), se comprobó directamente en la fachada mediante un dinamómetro de la marca Positext modelo AT-CM y de acuerdo a la UNE-EN 1015-12:2000. Los resultados obtenidos fueron satisfactorios como se indica en la Tabla 3 (8).

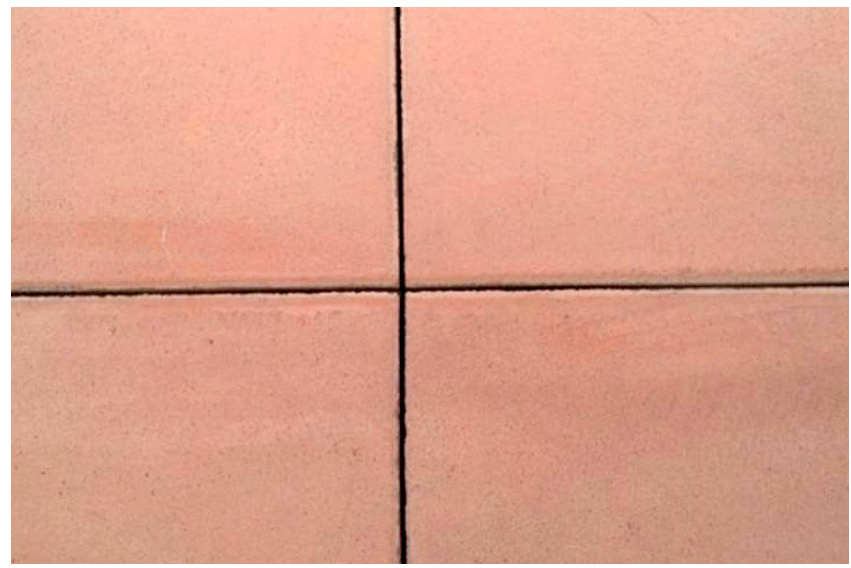

Figura 15. Corte del revoco y enfoscado para conformar las juntas de retracción.

Tabla 2. Resultados de caracterización del revoco aplicado.

\begin{tabular}{|c|c|c|c|c|}
\hline Densidad Kg/m & Flexión (MPa) & $\begin{array}{c}\text { Compresión } \\
\text { unitaria (MPa) }\end{array}$ & $\begin{array}{c}\text { Velocidad ultra- } \\
\text { sonidos (m/s) }\end{array}$ & $\begin{array}{c}\mathbf{E} \\
\text { dinámico (GPa) }\end{array}$ \\
\hline 1.675 & 0,40 & 1,20 & $1.338,30$ & 3,00 \\
\hline
\end{tabular}

Fuente Euroconsult.

Tabla 3. Caracterización de los revocos aplicados.

\begin{tabular}{|c|c|l|l|}
\hline Ensayo & $\begin{array}{c}\text { Resistencia a tracción } \\
\text { (MPa) }\end{array}$ & \multicolumn{2}{|c}{ Tipo de rotura } \\
\hline 1 & 0,31 & B (rosa/blanco) & Rotura cohesiva -rotura en el mortero \\
\hline 2 & 0,30 & A (rosa) & Rotura cohesiva -rotura en interfaz entre mortero y soporte \\
\hline 3 & 0,33 & B (blanco) & Rotura cohesiva -rotura en el mortero \\
\hline
\end{tabular}

Fuente: Euroconsult. 


\subsection{Limpieza y consolidación superficial}

Todas las molduras se limpiaron previamente a la consolidación con microesferas de vidrio, a baja presión controlable (1,5 bares), que no afectó a las superficies, principalmente las aristas. Se aplicó también biocida en las áreas afectadas por organismos.

Una vez reancladas las molduras macizas se aplicó un consolidante superficial (9) que no forma película, en base a ésteres etílicos de ácido silícico, que reacciona con la humedad atmosférica y se transforma en gel de sílice y alcohol etílico.

\subsection{Cobertura de elementos salientes}

La protección de los planos superiores de los elementos salientes (molduras, guardapolvos y vierteaguas) se realizó con plancha de zinc envejecido «Quartz», de o,82 mm de espesor, con el debido goterón, con un geotextil de separación de la superficie a proteger para facilitar su transpiración, con engatillado en todas las uniones entre chapas y con faldón anclado a la pared y sellado contra ella (Figura 16). El faldón plegado hacia arriba en su encuentro con la fachada variaba según su situación para proteger la junta constructiva con el revoco; la lámina está anclada al paño de fachada y el encuentro sellado con silicona de color similar al revoco. Estas piezas de protección no afectan a la apariencia original de las molduras ni de la fachada, como se puede apreciar en la Figura 17.

\section{CONCLUSIONES}

Para una correcta toma de decisiones en la intervención se ha manifestado necesaria la caracterización previa de elementos y materiales en base a observación y ensayos.

Con carácter general la consolidación de revestimientos de fachadas de edificios históricos, para evitar fisuras, des-

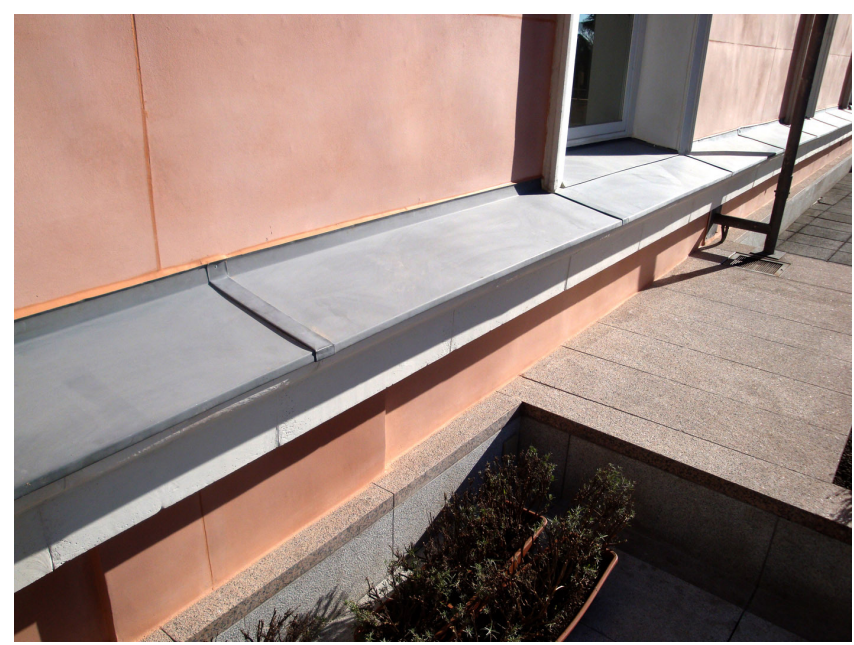

Figura 16. Cobertura de cornisa inferior con plancha de zinc engatillada. prendimientos, reducir la infiltración de agua y mejorar la cohesión, implica la adición de armados resistentes a la corrosión, como mallas de fibra de vidrio, compatibles en las interfaces de adherencia entre los materiales existentes y los nuevos.

Las molduras huecas y macizas demandan un reanclado cuyo número puede variar según las piezas que las componen y las condiciones de empotramiento o sujeción, así como la aplicación de consolidantes superficiales una vez aplicados los morteros de restauración y realizada la reintegración de las partes erosionadas.

Cuando existen piezas rotas que amenazan su estabilidad, se requiere la reproducción de réplicas preferentemente con el mismo tipo de material.

Teniendo en cuenta la exposición de elementos de grandes longitudes o superficies, resulta imprescindible la apertura de juntas de retracción, con sus respectivos sellados con material elastomérico, tanto en molduras como en revocos en su caso, manteniendo la continuidad de las mismas en caso de juntas constructivas y de dilatación estructural. La distancia entre estas juntas de retracción dependerá del elemento constructivo y la situación climática.

Finalmente, resulta totalmente necesaria la cobertura total de superficies horizontales y salientes con materiales de impermeabilización, preferentemente plancha de zinc, asegurando la posibilidad de transpiración incluyendo un elemento separador entre el elemento constructivo y la chapa de zinc, como una manta geotextil.

\section{AGRADECIMIENTOS}

$\mathrm{Al}$ arquitecto conservador del Senado, Ignacio Moreno y a la empresa KALAM.

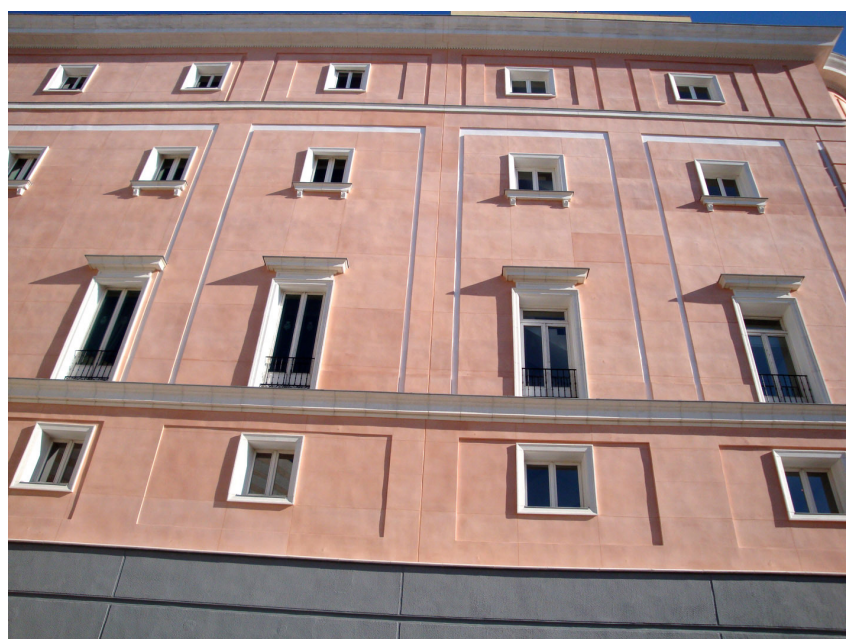

Figura 17. Aspecto de la fachada una vez terminadas las obras (febrero 2014). 


\section{REFERENCIAS}

(1) AENOR. (2012). UNE-EN 15898 - Conservación del patrimonio cultural - Principales términos generales y definiciones. Asociación Española de Normalización.

(2) Ambrós-Escanellas, M. (1951, junio). Presupuesto general del proyecto de reconstrucción de las fachadas. Madrid: Archivo del Senado.

(3) Bustamante, R., Monjo, J., Sánchez de Rojas, M.I. (2012), Los materiales utilizados en la ejecución de la bóveda encamonada del Salón de Plenos del Senado de España. Materiales de Construcción, 62(306): 299-307, doi: http://dx.doi. org/10.3989/mc.2012.61310.

(4) Bustamante, R., Monjo, J., Sánchez de Rojas, M.I. (2012). Aspectos constructivos del aplacado de piedra artificial (arcosita "Butsems") de la fachada sur del Palacio del Senado de España. Materiales de Construcción, 62(306): 309-318, doi: http://dx.doi.org/10.3989/mc.2012.61510.

(5) Bustamante, R., Monjo, J. (2012). Rehabilitación de molduras huecas de piedra artificial. En Actas del $4^{\circ}$ Congreso de Patología y Rehabilitación de Edificios, resumen p. 41, Santiago de Compostela: Ed. Colegio Oficial de Arquitectos de Galicia.

(6) CTS ESPAÑA. Ficha técnica de barras corrugadas.

(7) Euroconsult, S.A. (2013, 26 noviembre). Informe de ensayos de resistencia a flexión y compresión en morteros endurecidos y módulo de Young dinámico. Documentación de las obras del Senado. Madrid: Euroconsult, S.A.

(8) Euroconsult, S.A. (2014, 5 marzo). Informe de ensayos. Determinación in situ de adherencia por tracción. Documentación de las obras del Senado. Madrid: Euroconsult, S.A.

(9) García-de Miguel, J.M. (2009). Consolidación y Protección. En Tratamiento y Conservación de la Piedra, el Ladrillo y los Morteros en Monumentos y Construcciones, Cap. 34. Madrid: Ed. Consejo General de la Arquitectura Técnica en España. 